\title{
DISCURSO DE POSSE DO PROFESSOR ANTONIO MAGALHÃES GOMES FILHO COMO DIRETOR DA FACULDADE DE DIREITO DA UNIVERSIDADE DE SÃO PAULO
}

\author{
INAUGURATION SPEECH OF PROFESSOR ANTONIO MAGALHÃES GOMES FILHO AS DIRECTOR \\ OF THE FACULDADE DE DIREITO DA UNIVERSIDADE DE SÃO PAULO
}

A minha ligação com esta Faculdade é bem antiga.

Para ser exato, começou no ano de 1858 quando o jovem José Maria de Moura Leite deixou a cidade de Campanha, na então Província de Minas Gerais, para se transferir para esta São Paulo, com o propósito de cursar a Academia de Direito instalada no convento dos franciscanos. Deve ter vindo a cavalo ou em lombo de burro, pois outro meio de transporte não permitiam os antigos caminhos imperiais, e aqui passou a morar em uma república de estudantes na Rua Tabatinguera. Concluído o curso, no qual foi aprovado com o conceito plenamente, recebeu das mãos do Diretor desta Casa, o Conselheiro Padre Manoel Joaquim do Amaral Gurgel, o título de bacharel em ciências jurídicas e sociais, como está certificado no diploma de pergaminho expedido em 1862.

Sua filha mais nova, Dona Yayá, minha avó paterna, sempre conservou esse documento, exibindo-o em sua casa na antiga Rua do Bispo, depois Desembargador Eliseu Guilherme, em lugar de destaque, entre os retratos e outros objetos da memória familiar, o que demonstra a grande importância que dava à passagem do meu bisavô por esta Faculdade.

Também pelo lado materno, minha relação com estas Arcadas é praticamente centenária, pois no começo do século XX os irmãos de minha outra avó, Dona Judith - Heitor, Armando, Sebastião e Edgar de Moura Bittencourt -, agora pelos trilhos da Mogiana, deixaram a sua Ribeirão Preto com o mesmo destino e com o mesmo propósito. Deles, com quem tive o privilégio de conviver, ouvi muitos relatos palpitantes e divertidos sobre sua intensa vida estudantil na Academia do Largo de São Francisco.

Tio Heitor, grande mestre na arte de conversar e gracejar, comentava com riqueza de detalhes sua viagem ao Rio de Janeiro, em comitiva de estudantes de sua turma, a de 1920, que se dirigiu à então Capital da República para convidar para paraninfo, o grande Rui Barbosa, que produziu para a solenidade de formatura a célebre "Oração aos Moços", lida por Reinaldo Porchat.

Sebastião de Moura Bittencourt, o tio Tãozinho, da Turma de 1929, foi bastante ativo na política universitária, chegando mesmo a ser cogitado para a Presidência do XI de Agosto. Seu irmão mais moço, Edgard, da Turma de 1930, que depois brilhou na vida profissional como magistrado e jurista destacado pela ousadia na defesa de teses inovadoras no direito de família, fez parte da diretoria do XI, em 1927 Os dois também marcaram sua presença na vida estudantil participando das "caravanas acadêmicas" Elas consistiam em visitas a cidades do interior paulista, onde conferências, cantos e 
representações teatrais proporcionavam ao meio local momentos de civismo e cultura, levados pelos jovens acadêmicos.

Assim, ao matricular-me no curso de bacharelado, em 1965, já me eram bastante conhecidas a História e as estórias desta Faculdade. Lembro bem que nas casas de meus tios Luiz Toloza Oliveira e Costa turma de 1938 -, , Joaquim Antonio Bittencourt Couto - turma de 1944 - e Gabriel Magalhães Gomes - turma de 1948 -, as comemorações familiares incluíam sempre a saudação do homenageado com o solene "quim quim querum" uma das mais marcantes tradições desta Casa.

Faço essas referências pessoais douta Congregação - não apenas para registrar o caráter emocional da minha ligação com esta Faculdade, mas principalmente para sublinhar o meu respeito pelo seu passado e suas tradições.

Mas, ao assumir a direção desta Faculdade para um mandato que vai até o ano de 2014, não posso pensar senão no presente e no futuro, sem que isso possa ser confundido com desprezo pelos valores do nosso glorioso passado. Creio que é hora de pensar na São Francisco do seu bicentenário, em 2027, que não está tão distante.

Como observou Eric Hobsbawn, mesmo que se tente retroceder o relógio, isso não restabelece de fato os velhos tempos, pois quando a mudança social acelera ou transforma a sociedade para além de um certo ponto, o passado deve cessar de ser o padrão do presente e pode, no máximo, tornar-se um modelo para o mesmo. Ele agora se torna uma máscara para a inovação, pois já não expressa a repetição daquilo que ocorreu antes, mas ações que são, por definição, diferentes das anteriores.

Por isso as tradições, como práticas de natureza ritual ou simbólica que visam inculcar certos valores e normas de comportamento através da repetição, podem afetar outra exigência da prática, que é a capacidade de lidar com situações imprevistas e originais.

A propósito das tradições, em 11 de Agosto de 1960, neste mesmo Salão Nobre, dissertando sobre "As Faculdades de Direito na História do Brasil", o Professor Miguel Reale também afirmava que "há uma tradição radiosa que nos faz viver o passado, historicisticamente, como atualidade presente; e há uma tradição obscura e triste, feita de renúncias irreparáveis, pesando como capa de chumbo sobre os ombros de uma juventude que aguarda passivamente o futuro, como se este fosse uma dádiva e não uma conquista"

Desde a sua criação, em 1827 - e por muito tempo -, esta Escola foi sobretudo um centro de formação política para a elite dirigente do País, não sendo casual que oito Presidentes da República Velha tivessem passado por aqui. Hoje, com certeza, o que se espera de uma Faculdade de Direito é que forme profissionais do direito para um mercado de trabalho cada vez mais competitivo e exigente, sem que isso signifique abrir mão de uma preparação humanística mais geral, voltada à compreensão das grandes questões da sociedade contemporânea. 
Nos últimos três anos e meio, sob a dinâmica condução do Professor João Grandino Rodas, hoje Magnífico Reitor da Universidade de São Paulo, esta Faculdade passou por importantes mudanças, tanto no âmbito do ensino como no da sua estrutura física. Foi aprovada e implantada nova grade curricular, com a adequação das disciplinas àquelas exigências de sólida formação profissional e oferecimento de muitas matérias optativas, o que também implicou a divisão de turmas, indispensável para a eficiência pedagógica.

Com isso, tornaram-se insuficientes as instalações deste Prédio Histórico e do seu Anexo, o que, por sua vez, ensejou a desapropriação de edifícios vizinhos para atender às novas necessidades de espaço para as nossas atividades. Compreendeu-se também a urgência em dotar as nossas salas de aula e outras instalações dos recursos modernos de informática e telecomunicações, visando ao melhor aproveitamento acadêmico.

Como todo processo de mudança, tudo isso tem gerado algum desconforto, transtorno e até a insatisfação de alguns, o que é compreensível, mas não pode, de modo algum, justificar qualquer retrocesso, ainda que sob o argumento da tradição.

Daí a minha proposta já apresentada informalmente a alguns colegas professores, alunos, antigos alunos e servidores , que agora faço pública, ao assumir a Diretoria, no sentido de reunir os esforços e opiniões de toda a comunidade acadêmica para a discussão de um plano diretor para a modernização do ensino e do espaço físico na nossa Faculdade, assim como foi feito em outras Unidades da Universidade de São Paulo, como a Faculdade de Medicina.

Creio firmemente que somente com o debate amplo, transparente e democrático das idéias será possível chegar não só ao entendimento sobre os rumos desse processo de transformação, como, principalmente, à obtenção dos recursos necessários à sua efetiva implementação.

Essa não será, portanto, uma tarefa da Diretoria, mas deverá constituir um esforço conjunto de todos os membros da comunidade acadêmica - docentes, estudantes, antigos alunos e servidores a que espero poder contar com o apoio da Reitoria da Universidade, dos poderes públicos, da iniciativa privada e de todos, enfim, que como eu amam verdadeiramente esta Faculdade.

Não poderia encerrar sem fazer uma série de indispensáveis e sinceros agradecimentos.

Em primeiro lugar, aos membros da Congregação e dos Conselhos Departamentais pela indicação - quase unânime - na lista tríplice encaminhada ao Magnífico Reitor para assumir a função de diretor. Essa circunstância, que muito me envaidece, cria, por outro lado, uma grande responsabilidade, a de manter esse apoio pelos quatro anos de mandato. 
Ao Magnífico Reitor da Universidade de São Paulo, Professor João Grandino Rodas, pela escolha do meu nome numa lista que incluía dois dos mais insignes mestres desta Casa: Tércio Sampaio Ferraz Júnior e Celso Lafer.

Aos oradores que me precederam, Professor Miguel Reale Júnior e Acadêmico Victor Magalhães Gadelha, pelas generosas palavras de apreço e confiança.

Por último, mas não menos importante, agradeço, sensibilizado, a honrosa presença de todos nesta solenidade de posse.

Às Digníssimas autoridades já nomeadas e aos colegas do Conselho Universitário e de outras unidades e instituições de ensino.

Aos professores desta Casa, aos seus ex-diretores, aos meus professores, lembrando especialmente a minha orientadora no doutorado, Professora Ada Pellegrini Grinover.

Aos estudantes de hoje; aos meus alunos, especialmente os meus afilhados das turmas de 1991, 1994, 1996, 2000, 2003 e 2006; aos antigos alunos, lembrando com emoção os meus colegas da Turma de 1969;

Aos nossos dedicados e competentes servidores técnico-administrativos;

Aos meus amigos do Ministério Público, da magistratura e advocacia;

À minha família: meus tios, minhas irmãs, meu cunhado, primos e sobrinhos e, muito carinhosamente, à Isabela e às nossas filhas Mariângela e Gabriela.

Arcadas, 23 de março de 2010. 


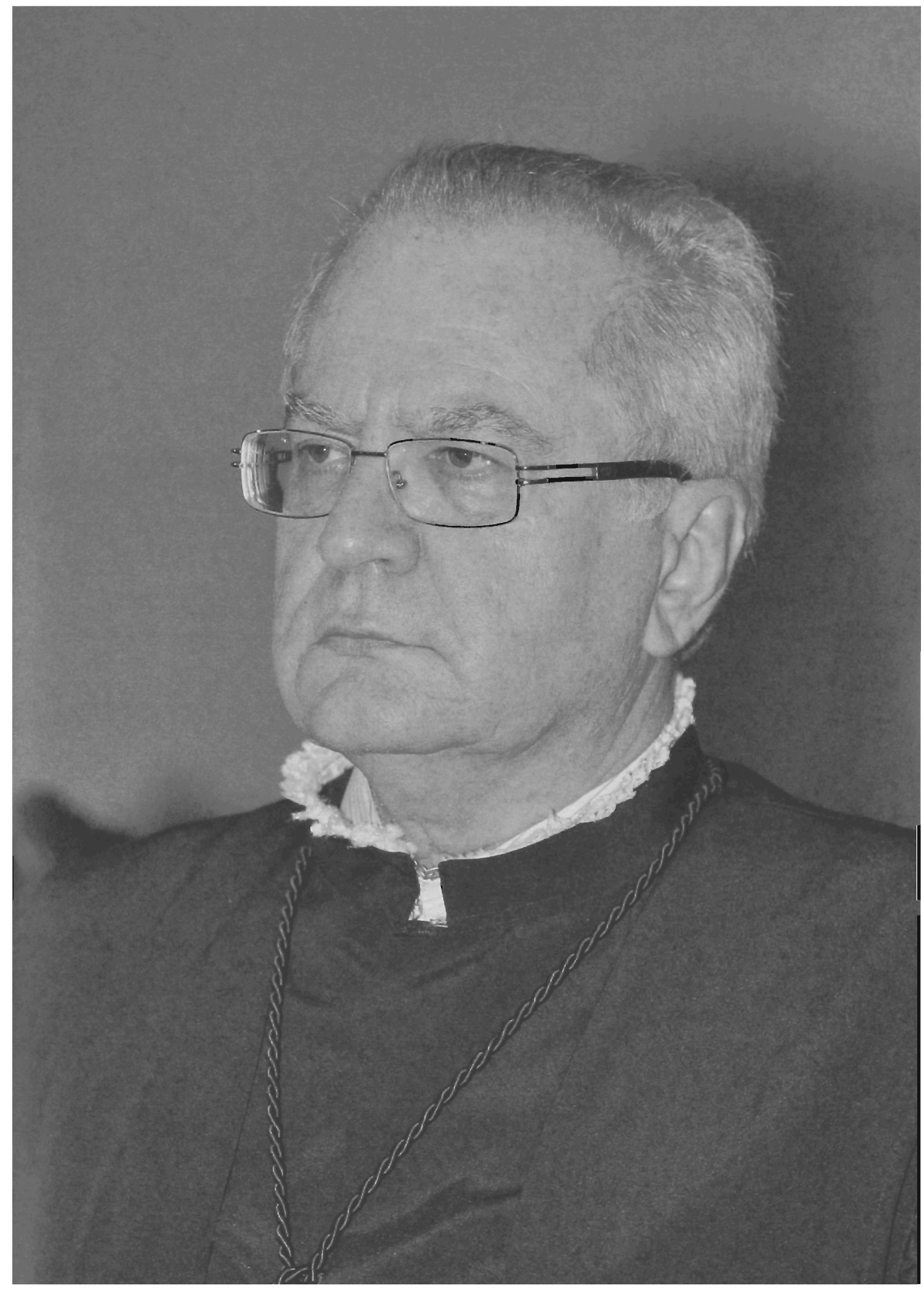

Professor Antonio Magalhães Gomes Filho 